\title{
Economic values and expected effect of selection index for pathogen-specific mastitis under Danish conditions
}

\author{
L. P. Sørensen, ${ }^{*} \dagger^{1}$ T. Mark, ${ }^{*} M$. K. Sørensen, $† \ddagger$ and S. Østergaard§ \\ *University of Copenhagen, Faculty of Life Sciences, Department of Basic Animal and Veterinary Sciences, DK-1870 Frederiksberg C, Denmark \\ †University of Aarhus, Faculty of Agricultural Sciences, Department of Genetics and Biotechnology, Research Centre Foulum, DK-8830 Tjele, \\ Denmark \\ ‡Danish Agricultural Advisory Service, Udkaersvej 15, Skejby, DK-8200 Aarhus N, Denmark \\ §University of Aarhus, Faculty of Agricultural Sciences, Department of Animal Health and Bioscience, Research Centre Foulum, DK-8830 Tjele, \\ Denmark
}

\begin{abstract}
The objectives of this study were 1) to estimate costs related to 5 different pathogen-specific mastitis traits (susceptibility to different pathogens causing mastitis in dairy cattle) and unspecific mastitis, and 2) to compare selection differentials for an udder health index consisting of 5 different pathogen-specific mastitis traits and lactation average somatic cell count from 5 to 170 $\mathrm{d}$ after first calving (LASCC170) with another index consisting of 1 unspecific mastitis trait and LASCC170. Economic values were estimated for mastitis caused by Staphylococcus aureus, Streptococcus dysgalactiae, Escherichia coli, coagulase-negative staphylococci, and Streptococcus uberis using a stochastic simulation model (SimHerd IV). Mastitis incidences for SimHerd IV were from incidences of mastitis treatments in primiparous Danish Holstein cows calving in 2007. Estimated costs ranged from $€ 149$ to $€ 570$ per mastitis case and were highest for contagious pathogens such as Staph. aureus and coagulase-negative staphylococci and lowest for Strep. dysgalactiae and Strep. uberis. The value for unspecific mastitis was €231 per case. Selection differentials (in $€$ ) were estimated for 4 different selection indices, including 1) unspecific mastitis, 2) unspecific mastitis and LASCC170, 3) 5 pathogen-specific mastitis traits and unspecific residual mastitis (unspecific mastitis treatments minus mastitis treatments caused by the 5 pathogens), and 4) as index 3 including LASCC170. The breeding goal was identical to selection index 3 . Mastitis data from primiparous cows calving from 1998 to 2008 were used to estimate genetic parameters of the mastitis traits using linear models and AI-REML algorithm. These parameters were used for construction of the selection index equations. For the selection indices, information sources were measurements of
\end{abstract}

Received June 22, 2009.

Accepted September 20, 2009.

${ }^{1}$ Corresponding author: LarsPeter.Sorensen@agrsci.dk mastitis treatments and LASCC170 from 50, 80, or 130 daughters of a bull as well as measurements of mastitis treatments from 1,000 progeny of the bull's sire and 1,000 daughters of his maternal grandsire. Differences in selection differentials were marginal among the 4 indices. Without considering LASCC170, the selection differential of an unspecific mastitis index was €0.4 $(<1 \%)$ better than that of a pathogen-specific index. On the other hand, the selection differential of the pathogenspecific index was $€ 0.3(<1 \%)$ better than that of an unspecific index when LASCC170 was included in the indices. Reliabilities of the selection indices were 0.62 to 0.67 (80 daughters) and were proportional to the selection differential. Changing the number of daughters to 50 or 130 did not change ranking of the indices. Heritabilities of the pathogen-specific traits were very low $\left(h^{2}\right.$ $=0.005-0.021)$ compared with unspecific mastitis $\left(h^{2}=\right.$ 0.062), which may limit the selection differential of the pathogen-specific index.

Key words: simulation, mastitis, genetic parameter, pathogen

\section{INTRODUCTION}

Mastitis is the most prevalent production disease in Danish dairy herds. Economic losses related to reduced milk yield, discarded milk, penalties caused by high bulk tank SCC (BTSCC), treatment costs, increased labor, and increased culling rate are substantial (e.g., Halasa et al., 2007). Also, reduced animal welfare and other ethical issues, such as biosecurity concerns caused by increased use of antibiotics, are associated with mastitis in dairy cows.

Over the past couple of decades, strong emphasis has been placed on the development of mastitis control programs. For example, the Norwegian prevention program, partly described by Østerås et al. (2007), has been successful at decreasing the prevalence of mastitis. The authors described 3 main reasons for this decrease: effect of preventive management programs, effect of changed attitudes of the farmers toward treatment, and 
genetic improvement. In contrast to the first 2 reasons, the effect of genetic change is permanent to the dairy population. Therefore, it is of interest to increase the genetic gain of resistance to mastitis.

The udder health index calculated by the joint Nordic cattle genetic evaluation (Denmark, Finland, and Sweden) includes both direct information on udder health (number of mastitis treatments) and indirect information from SCC, fore udder attachment, and udder depth. The genetic trend for udder health in Denmark has improved over the past $10 \mathrm{yr}$; on average, the increase has been 0.3 index units per year $($ mean $=100$, $\mathrm{SD}=10$ ) for AI-tested Holstein bulls (Danish Cattle Association, 2009). However, the average mastitis incidence has remained unchanged since 2003. There could be several reasons why the improving genetic trend for udder health is not reflected at the phenotypic level, such as poorer management, increased infection pressure caused by increasing farm size, or time needed for genetic changes to be expressed in future generations.

Studies (e.g., Steine, 1998) have shown that it is possible to change susceptibility to mastitis through genetic selection despite the low heritability of the trait. Therefore, effective selection for mastitis resistance can be expected as long as proper recording and sufficiently large daughter groups are used for progeny testing (Heringstad et al., 2000). However, focus should still be on improvement of current udder health indices. Inclusion of pathogen-specific mastitis traits, defined as susceptibility to mastitis caused by different pathogens, in an udder health breeding program may prove beneficial because pathogen information provides direct measures of udder infections in contrast to mastitis treatments regardless of the causative pathogen (unspecific mastitis). Current mastitis traits include treatments where no pathogens have been isolated, providing incomplete information about mastitis resistance. However, heritabilities on the underlying scale of pathogen-specific mastitis traits are low $\left(h^{2}=0.039-0.079\right)$ in contrast to unspecific mastitis $\left(h^{2}=0.114\right)$ as found by Sørensen et al. (2009a). Therefore, genetic gain may be limited when using pathogen-specific mastitis traits instead of an unspecific mastitis trait. However, when several pathogen-specific mastitis traits are used simultaneously in an udder health index, the low heritabilities may be counterbalanced by the genetic correlations between the traits. The genetic correlations between various pathogen-specific mastitis traits are high $\left(\mathrm{r}_{\mathrm{a}}=\right.$ 0.45-0.77; Sørensen et al., 2009a).

In a selection index, the relative importance of each trait is based on its economic value. Østergaard et al. (2005) used a stochastic simulation program to determine increments in net returns when mastitis caused by single pathogens was eliminated in a model herd. They investigated mastitis caused by 8 different pathogens and estimated an increase in net return between $€ 0.5$ and $€ 42$. This study indicated that economic values of different pathogens differ. Considering the differences in these values, it may be beneficial to use an udder health index consisting of several pathogen-specific mastitis traits. However, in Østergaard et al. (2005), incidences of the different pathogens were determined from a selected data set, so it is necessary to reestimate economic values using field data.

The aims of this study were to 1 ) estimate economic values for unspecific mastitis and mastitis caused by the 5 most common pathogens in the Danish Holstein population, and 2) compare selection differentials for udder health using an index containing multiple pathogen-specific mastitis traits with an index containing unspecific mastitis only.

\section{MATERIALS AND METHODS}

\section{Parameterization of Stochastic Model Used to Estimate Economic Values}

Economic values (i.e., total costs associated with a case of mastitis) of unspecific mastitis and mastitis caused by Staphylococcus aureus, Streptococcus dysgalactiae, Escherichia coli, CNS, and Streptococcus uberis were estimated using the SimHerd IV program (Østergaard et al., 2005). SimHerd IV is a bioeconomic model with stochastic elements used to simulate changes in a dairy herd. The model simulates state changes over time of a dairy herd including young stock; the simulation unit in the model is the individual animal. Technical key figures from simulating a default herd are shown in Table 1. Details such as death rates of calves at different time intervals, conception rates for different groups of cows, involuntary culling rates, feeding levels, and strategies for different groups of animals were also simulated (data not shown). Applied prices and costs were updated to 2008 values (Table 2). In this version of SimHerd, fixed costs for replacement heifers were not taken into account; therefore, the value of a replacement heifer equaled the cost related to rearing a heifer (feed costs and other variable costs).

The simulations were done over time with weekly time increments. The state of each animal was defined by age, parity, lactation stage, milk yield, BW, reproductive status, and disease status. Discrete events such as heat detection, conception, sex and viability of calf, disease occurrence, culling, and mortality were triggered stochastically using random numbers from relevant distributions.

Baseline Risk Functions. Each mastitis type was modeled at cow-level as a separate disease without di- 
Table 1. Default parameterization of the model simulating economic consequences of a general production and management strategy

\begin{tabular}{ll}
\hline Parameter & Default value \\
\hline Size of dairy herd & $100 \mathrm{cows} / \mathrm{yr}$ \\
Replacement rate & $32 \%$ \\
Dead cows & $5.3 \mathrm{cows} / \mathrm{yr}$ \\
Stillborn calves & $7.0 \mathrm{calves} / \mathrm{yr}$ \\
Dead calves (heifers) after calving & $3.0 \mathrm{calves} / \mathrm{yr}$ \\
Calving age at first calving & $27 \mathrm{mo}$ \\
Yield capacity & $9,400 \mathrm{~kg}$ of ECM $\mathrm{EC}^{1} / \mathrm{cow}$ \\
Average daily milk yield for primiparous cows, first $24 \mathrm{wk}$ & $28.3 \mathrm{~kg}$ of ECM \\
Average daily milk yield for multiparous cows, first $24 \mathrm{wk}$ & $34.5 \mathrm{~kg}$ of ECM \\
Start AI (cows) after calving & $35 \mathrm{~d}$ \\
Start AI (heifers), age & $16.1 \mathrm{mo}$ \\
Insemination percentage ${ }^{2}$ (heifers) & $60 \%$ \\
Disease (cases per 100 cows) & \\
Milk fever & 4.3 \\
Displaced abomasum & 1.2 \\
Ketosis & 2.6 \\
Digital dermatitis & 20 \\
Sole ulcers & 4.0 \\
Other feet and leg problems & 25 \\
Calving difficulties & 1.1 \\
Retained placenta & 12.2 \\
Metritis & 6.3 \\
\hline
\end{tabular}

${ }^{1}$ Defined with reference to the first 24 wk of the third lactation.

${ }^{2}$ Number of inseminations relative to the expected number of heat detections in heifers required to be pregnant within 12 mo.

Table 2. Prices and costs under Danish production circumstances

\begin{tabular}{ll}
\hline Factor & Value \\
\hline Production & \\
Milk & $€ 0.32 / \mathrm{kg}$ of ECM \\
Withdrawn milk used for calves & $€ 0.256 / \mathrm{kg}$ of ECM \\
Correction of milk price for bulk tank SCC & $+1.8 \%$ \\
$\leq 200,000$ & $+0.9 \%$ \\
$200,000-300,000$ & $-3.6 \%$ \\
$400,000-500,000$ & $-9.0 \%$ \\
$>500,000$ & $€ 0.967 / \mathrm{kg}$ of BW \\
Livestock income & $€ 613 /$ animal \\
Slaughter cows & $€ 67 /$ animal \\
Slaughter heifers & $€ 1,467 /$ animal \\
Bull calves & $€-80$ to $€-7 /$ animal \\
Pregnant heifers & $€ 0.026 / \mathrm{MJ}{ }^{1}$ (lactating); $€ 0.024 / \mathrm{MJ}$ (dry) \\
Dead animals & $€ 0.256 / \mathrm{kg}$ of milk \\
Feed costs & $€ 0.034 / \mathrm{MJ}$ \\
TMR (cows) & $€ 0.024 / \mathrm{MJ}$ \\
Milk replacer & $€ 0.72$ and $€ 1.12 / \mathrm{d}$ \\
Concentrates (heifers) & \\
Roughage (heifers) & $€ 91 /$ case \\
Grazing first and second year & $€ 47-€ 192 /$ case \\
Veterinary costs & \\
Mastitis (all types) & $€ 40 /$ cow per year \\
Other diseases & $€ 13 /$ heifer per year \\
Other costs & $€ 9-€ 45 / \mathrm{AI}$ \\
Cows & $4 \%$ \\
Heifers & \\
AI & \\
Annual interest rate & \\
\hline
\end{tabular}

${ }^{1}$ Net energy for lactation (MJ).

${ }^{2}$ Covering average costs for bedding, milk recording, pregnancy test, additional veterinary assistance, and medication. 
Table 3. Variables describing risk of severity relative to moderate severity of mastitis cases for unspecific and pathogen-specific mastitis ${ }^{1}$ in SimHerd IV (Østergaard, 2005)

\begin{tabular}{|c|c|c|c|c|c|c|}
\hline Parameter & Unspecific $^{2}$ & AUR & DYS & $\mathrm{COL}$ & CNS & UBE \\
\hline Relative risk of case being subclinical (dry period) & 0.86 & 0.94 & 0.81 & 0.68 & 0.92 & 0.78 \\
\hline $\begin{array}{l}\text { Risk of chronic reduction in yield capacity relative } \\
\text { to the total risk of a clinical case }\end{array}$ & 0.03 & 0.05 & 0.025 & 0.1 & 0 & 0 \\
\hline
\end{tabular}

${ }^{1} \mathrm{AUR}=$ Staphylococcus aureus $; \mathrm{DYS}=$ Streptococcus dysgalactiae $; \mathrm{COL}=$ Escherichia coli $; \mathrm{UBE}=$ Streptococcus uberis.

${ }^{2}$ Weighted average of the pathogen-specific mastitis traits.

rect mutual interaction with other mastitis types. Each type of mastitis had its own set of variables for risk factors and effects of the disease. Detailed descriptions and references can be found in Østergaard et al. (2005). Unless otherwise mentioned, parameters were the same for all types of mastitis. The shapes of default baseline cow-level risk functions in different time intervals during lactation (defined as 5 different periods with regard to lactation stage) for all mastitis types (both clinical and subclinical cases) were based on the curve illustrated by Seegers et al. (2000). The levels of these curves were increased or decreased relative to an intercept and herd-level modifiers (e.g., season) and cow-level modifiers (e.g., milk yield, parity). The risk functions were modeled using a 3-line spline function with risk profile for parity 3 cows as a reference.

Risk Factors for Mastitis. The risk of contracting mastitis in the dry period was modeled relative to the risk during the first week of lactation. The default values were 0.43 in the week of drying off and 0.05 in the remaining dry period. The default values for the variables of effect of parity were given as odds ratios (OR) with parity 3 as a reference. The values were 0.60 and 0.75 for parity 1 and 2 , respectively (i.e., risk of mastitis increased with parity). The effect of milk yield on the risk of mastitis was modeled as OR of $1.04 / \mathrm{kg}$ of milk per day potential above herd average. Recurrence of mastitis that previously occurred more recently than last dry-off was assumed to have an OR of 1.2 , and mastitis that previously occurred before last dry-off was assumed to have an OR of 2.5 (same value for both clinical and subclinical mastitis). The OR of increased risk of mastitis caused by previous occurrence of other disease was assumed to be different from 1 only for milk fever $(\mathrm{OR}=1.1)$. Calendar seasons were assumed to have no effect on diseases. Contagious spread of mastitis across herdmates was not considered in the present study.

Effects of Mastitis. Severity of mastitis cases was divided into 5 categories: subclinical (both lactation and dry period), mild, moderate, severe, and chronic. Risk parameters by mastitis severity category and type of mastitis are shown in Table 3. For example, the chance of developing a subclinical case of $E$. coli mastitis in the lactating period was only $5 \%$ of the chance for developing a moderate clinical case of $E$. coli mastitis.

The default values for the effects of mild and severe cases compared with the effects of moderate clinical cases on feed intake, BW, milk yield, and SCC were specified to be 0.10 and 2.5, respectively (Seegers et al., 2003). The default values for the effects of subclinical cases compared with the effects of moderate clinical cases on these responses were specified to be 0.5. The permanent effect of chronic mastitis on yield capacity was specified to be a $15 \%$ reduction.

The effect of pathogen-specific mastitis on lactation profiles for SCC (Table 4) and milk yield (Table 5) was modeled through 3-phase linear spline functions. Modeling of SCC standard lactation profiles for uninfected cows was based on results from De Haas et al. (2002), and the values given in Table 4 are deviation from this standard curve. For example, SCC on the week of occurrence of Staph. aureus mastitis was 1,644,000 cells/ $\mathrm{mL}$ more than for an uninfected cow, 1 wk later it was 345,000 cells $/ \mathrm{mL}$, and 3 wk later it was 115,000 cells/ $\mathrm{mL}$. After wk 3, SCC continued to decline until the SCC curve for the infected animal reached the level of the standard curve from an uninfected animal. Effect on milk yield was also modeled relative to a standard milk yield curve for uninfected cows. For unspecific mastitis, the reduction on the week of occurrence was $15 \%$, and 1 and 2 wk after the week of occurrence the yield reduction was $81 \%$ relative to the reduction in week of occurrence. Thereafter, the effect reduced by $0.27 \% / d$ relative to the week of occurrence.

Daily weight gain was unaffected by mastitis occurrence in the model because this effect was counterbalanced by the indirect effects of reduced feed intake and milk yield. Milk withdrawal was based on 7-d withdrawal from the day of occurrence. Discarded milk was fed to calves and the economic value was equal to $80 \%$ of the value of sold milk, which is the same price as for 
Table 4. Default values for the 3-phased linear spline function for modeling direct SCC $\times 1,000$ increase relative to a standard nonmastitis SCC curve caused by different types of mastitis

\begin{tabular}{|c|c|c|c|c|c|c|}
\hline \multirow{2}{*}{$\begin{array}{l}\text { Time relative to mastitis } \\
\text { occurrence }\end{array}$} & \multicolumn{6}{|c|}{ Mastitis type $^{1}$} \\
\hline & Unspecific $^{2}$ & AUR & DYS & $\mathrm{COL}$ & CNS & UBE \\
\hline Week of occurrence & 1,693 & 1,644 & 1,774 & 1,666 & 1,666 & 1,788 \\
\hline 1 wk after occurrence & 439 & 345 & 373 & 417 & 483 & 590 \\
\hline 3 wk after occurrence & 192 & 115 & 160 & 150 & 267 & 250 \\
\hline Daily slope afterward & -889 & -559 & $-1,118$ & -566 & $-1,000$ & $-1,395$ \\
\hline
\end{tabular}

milk replacer (Table 2). The risk of death in the week of onset of a clinical mastitis case was 0.02 for E. coli, 0.003 for the remaining 4 pathogens, and 0.0052 for unspecific mastitis.

Increased labor caused by mastitis was not included in SimHerd IV. Assuming that the amount of extra labor associated with mastitis was the same for all pathogens, this effect would only scale the values of each type of mastitis. For the purpose of this study, the absolute cost associated with a case of mastitis was not important in contrast to the relative differences between costs associated with different types of mastitis.

Calibration of Simulation Model. The model was calibrated using incidences of mastitis treatments in primiparous Danish Holstein cows calving for the first time in 2007 and did not include treatments in the dry period. The incidence of unspecific mastitis was 0.24 cases (first case only) per lactation (defined as -15 to $300 \mathrm{~d}$ after calving). The frequencies of pathogenspecific mastitis were $0.20,0.07,0.09,0.21$, and 0.12 for Staph. aureus, Strep. dysgalactiae, E. coli, CNS, and Strep. uberis, respectively, which implied incidences of pathogen-specific mastitis cases per lactation of 0.048, $0.017,0.022,0.050$, and 0.029 (e.g., $0.2 \times 0.24=0.048$ ), respectively. The remaining part of the 0.24 cases $(0.074$ cases $=$ residual mastitis) consisted of mastitis treatments caused by pathogens other than the 5 pathogens investigated in the present study, mastitis treatments with no growth of pathogens, or mastitis treatments without corresponding pathogen information. Because the true distribution of pathogens within this group was unknown, it was assumed that the distribution of pathogens was the same as for the group with pathogen information and that effects of pathogens other than the 5 used in the present study were minor. Hence, parameters for unspecific mastitis were determined as the weighted averages of the parameters for the 5 pathogen-specific mastitis traits (weighted by disease incidence). The intercept for each pathogen-specific mastitis trait was calibrated to fit the incidence of the pathogen-specific mastitis traits in parity 1 as close as possible. The effect of parity on the risk of mastitis was kept constant (i.e., calibrating to a different incidence in parity 1 also changed incidences in multiparous cows).

\section{Estimated Economic Values}

Two separate analyses were performed for pathogenspecific and unspecific mastitis, respectively. Six scenarios were built into the first and 2 into the second analysis.

In the first analysis, scenario 1-1 (default scenario) kept all pathogen-specific mastitis traits at their default risk at occurrence. In scenarios 1-2 to 1-6, 1 pathogen

Table 5. Default values for the 3-phased linear spline function for modeling direct milk reduction relative to a standard nonmastitis milk yield curve caused by different types of mastitis

\begin{tabular}{|c|c|c|c|c|c|c|}
\hline \multirow{2}{*}{$\begin{array}{l}\text { Time relative to mastitis } \\
\text { occurrence }\end{array}$} & \multicolumn{6}{|c|}{ Mastitis type $^{1}$} \\
\hline & Unspecific $^{2}$ & AUR & DYS & $\mathrm{COL}$ & CNS & UBE \\
\hline Week of occurrence & 15 & 17 & 18 & 34 & 3 & 18 \\
\hline 1 wk after occurrence ${ }^{3}$ & 0.81 & 0.74 & 0.86 & 0.41 & 1 & 0.86 \\
\hline 2 wk after occurrence ${ }^{3}$ & 0.81 & 0.74 & 0.86 & 0.41 & 1 & 0.86 \\
\hline Daily slope after $2 \mathrm{wk}$ postoccurence ${ }^{3}$ & -0.0027 & -0.0019 & -0.0061 & -0.0029 & 0 & -0.0061 \\
\hline
\end{tabular}

${ }^{1} \mathrm{AUR}=$ Staphylococcus aureus $; \mathrm{DYS}=$ Streptococcus dysgalactiae $; \mathrm{COL}=$ Escherichia coli $; \mathrm{UBE}=$ Streptococcus uberis.

${ }^{2}$ Weighted average of the pathogen-specific mastitis traits.

${ }^{3}$ Relative to the reduction in the week of occurrence. 
at a time was eliminated whereas the remaining pathogens were kept at default level. Thus, the difference in profit between scenario 1-1 and each of the scenarios 1-2 to 1-6 equaled the economic profit associated with elimination of a given pathogen from the dairy herd.

In scenario 2-1 of the second analysis, all pathogenspecific mastitis traits were set to an incidence of zero and unspecific mastitis to an incidence of 0.24 . In scenario 2-2, unspecific mastitis was set to no risk.

Each scenario was run for $20 \mathrm{yr}$ to reach convergence and the mean results of the last $10 \mathrm{yr}$ of simulation were used to study the effects of the scenarios. Each scenario was replicated in 1,000 simulation runs to ensure precise estimates. The economic value of each mastitis type was calculated as the difference between marginal contribution per cow from scenarios 1-1 and 1-2 to 1-6, and 2-1 and 2-2 in analyses 1 and 2, respectively, divided by the estimated incidence of the mastitis trait with scenario 1-1 and 2-1 as the references. The economic value of unspecific residual mastitis was assumed to be equal to the economic value of unspecific mastitis.

\section{Breeding Goal, Selection Indices, and Response to Selection}

Breeding Goal. The breeding goal (e.g., Hazel, 1943) was composed of the 5 pathogen-specific mastitis traits and unspecific residual mastitis. Lactation average SCC on d 5 to 170 of first lactation (LASCC170), which is currently used in the joint Nordic genetic evaluation for udder health, was included as an example of a correlated trait in some of the selection indices (see below). However, the economic value of LASCC170 was assumed to be zero as found by Pedersen et al. (2008) and was therefore not included in the breeding goal. The economic weights for mastitis traits were adopted from results of the SimHerd simulations.

Selection Indices. Four different selection indices were considered: 1) unspecific mastitis from all groups of relatives (bull, sire, maternal grandsire); 2) as index 1 , including indirect information for LASCC170 of the bull; 3) pathogen-specific mastitis (5 traits) and residual mastitis from all groups of animals (bull, sire, maternal grandsire); and 4) as index 3, including indirect information for LASCC170 of the bull. Figure 1 describes the information sources. Each of the 4 selection index scenarios considered 50, 80, or 130 bull daughters to test sensitivity to the number of progeny. Currently used as a correlated trait in the Nordic udder health index (Johansson et al., 2006), LASCC170 is thought to provide extra information, especially when progeny groups are small. Thus, it seems reasonable to use this trait for testing the effect of correlated information on selection differentials.

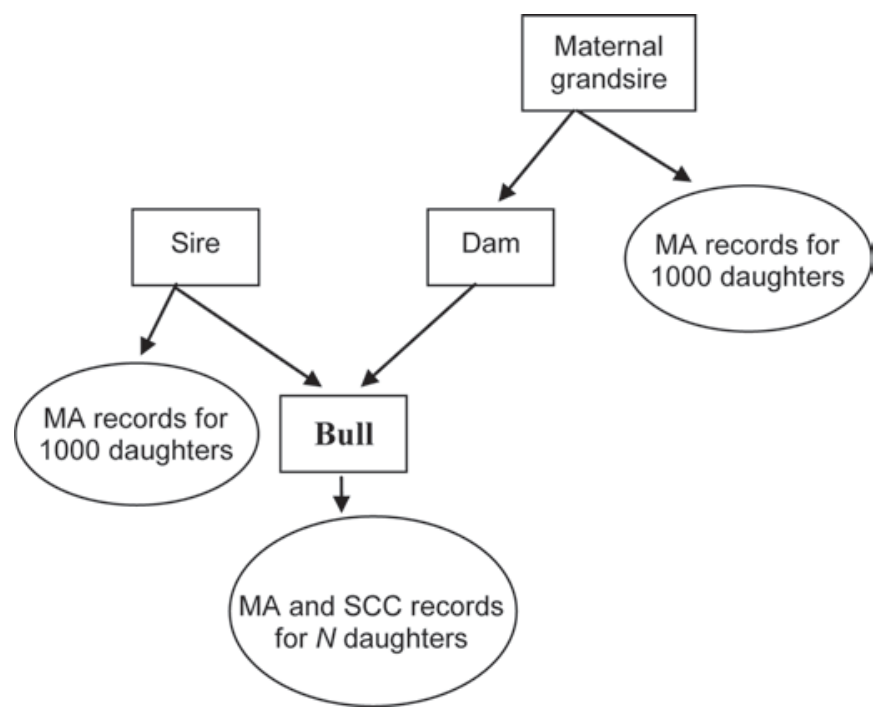

Figure 1. Information sources used for estimation of genetic superiority of selected bulls. Information about mastitis (MA) from all daughters and information about lactation average SCC from d 5 to 170 after calving (SCC) from $N$ daughters $(\mathrm{n}=50,80,130)$ were considered.

Genetic Superiority. Selection differentials (genetic superiority of selected animals) for the unspecific and the pathogen-specific mastitis traits were estimated using selection index theory as implemented in the selection index program (Wagenaar et al., 1995). For estimation of genetic superiority $(\boldsymbol{S}), 5 \%$ of tested bulls were selected, resulting in a selection intensity of 2.06 . Genetic superiority was calculated as $S=$ standard deviation of index $\times$ selection intensity, and the reliability was calculated as $r_{I \mathrm{~A}}^{2}$, where $r_{I \mathrm{~A}}$ is the accuracy of the index. The program requires parameters such as heritabilities of the traits and genetic and phenotypic correlation among the traits for construction of the selection index equations. Thus, genetic parameters of the traits in the selection indices were estimated (see next section).

Genetic Parameters. Data and editing procedures were adopted from Sørensen et al. (2009b). Briefly, records of mastitis treatments and test-day records of SCC were collected from primiparous Holstein cows calving for the first time between January 1998 and January 2008. Mastitis was defined as an all-or-none trait in the period -15 to $300 \mathrm{~d}$ after calving (period at risk), 1 if a cow was treated for mastitis and 0 otherwise. Only the first observed mastitis treatment for each cow was used. Pathogen-specific mastitis was differentiated from unspecific mastitis by distinguishing between mastitis with pathogen information and mastitis without. The LASCC170 was calculated as 


$$
\mathrm{LASCC}=\frac{1}{m} \sum_{i=1}^{m} \ln \left(\frac{\mathrm{SCC}_{i} / 1,000}{\mathrm{~mL}}\right)
$$

where $\mathrm{SCC}_{i}$ is the number of somatic cells per milliliter of milk on test-day $i$ if the test-day is between 5 and $170 \mathrm{~d}$ after calving, and $m$ is the number of test days. After editing, a total of 226,482 cows with records were included in the analyses.

The following bivariate linear sire-model was used to estimate genetic parameters for the mastitis traits and LASCC170:

$$
\mathbf{y}_{\mathrm{i}}=\mathbf{X}_{\mathrm{i}} \mathbf{b}_{\mathrm{i}}+\mathbf{W}_{\mathrm{i}} \mathbf{h}_{\mathrm{i}}+\mathbf{Z}_{\mathrm{i}} \mathbf{s}_{\mathrm{i}}+\mathbf{e}_{\mathrm{i}}
$$

where $\mathbf{y}_{\mathrm{i}}$ are vectors of observations of LASCC170 and either unspecific mastitis, residual mastitis, or mastitis caused by Staph. aureus, CNS, E. coli, Strep. dysgalactiae, or Strep. uberis; $\mathbf{b}_{\mathrm{i}}$ is a vector of trait-specific fixed effects; $\mathbf{h}_{\mathrm{i}}$ is a vector of random herd-year-season effects; $\mathbf{s}_{\mathrm{i}}$ is a vector of random effects of sire transmitting abilities; and $\mathbf{e}_{\mathbf{i}}$ contains residuals. $\mathbf{X}_{\mathbf{i}}, \mathbf{W}_{\mathrm{i}}$, and $\mathbf{Z}_{\mathrm{i}}$ are corresponding incidence matrices. The fixed effects were year-month of calving, calving age, and regression on the length of the period at risk defined as the number of days from $15 \mathrm{~d}$ before calving to the date of culling or to the end of the risk period. It was assumed that all cows with mastitis had a full risk period. For LASCC170, a regression on the length of the lactation after a case of mastitis had been observed was also included in the model. The covariance structure for the random effects was

$$
\operatorname{var}\left[\begin{array}{l}
\mathbf{h}_{1} \\
\mathbf{h}_{2}
\end{array}\right]=\mathbf{H}=\mathbf{H}_{0} \otimes \mathbf{I}_{n}
$$

where

$$
\mathbf{H}_{0}=\left[\begin{array}{cc}
\sigma_{h_{1}}^{2} & \sigma_{h_{12}} \\
\sigma_{h_{21}} & \sigma_{h_{2}}^{2}
\end{array}\right],
$$

$\mathrm{I}_{n}$ is an identity matrix of order $n$ equal to the total number of records for both traits, and $\otimes$ defines the Kronecker product,

$$
\operatorname{var}\left[\begin{array}{l}
\mathbf{s}_{1} \\
\mathbf{s}_{2}
\end{array}\right]=\mathbf{G}=\mathbf{G}_{0} \otimes \mathbf{A},
$$

where

$$
\mathbf{G}_{0}=\left[\begin{array}{cc}
\sigma_{\mathrm{s}_{1}}^{2} & \sigma_{\mathrm{s}_{12}} \\
\sigma_{\mathrm{s}_{21}} & \sigma_{\mathrm{s} 2}^{2}
\end{array}\right]
$$

and $\mathbf{A}$ is the additive relationship matrix,

$$
\operatorname{var}\left[\begin{array}{l}
\mathbf{e}_{1} \\
\mathbf{e}_{2}
\end{array}\right]=\mathbf{R}=\mathbf{R}_{0} \otimes \mathbf{I},
$$

where

$$
\mathbf{R}_{0}=\left[\begin{array}{cc}
\sigma_{\mathbf{e}_{1}}^{2} & \sigma_{\mathbf{e}_{12}} \\
\sigma_{\mathbf{e}_{21}} & \sigma_{\mathbf{e}_{2}}^{2}
\end{array}\right]
$$

and $\mathbf{I}$ is the identity matrix.

The variance and covariance components were estimated using the AI-REML algorithm (Jensen et al., 1997 ) included in the DMU package (Madsen and Jensen, 2006). Convergence was reached when the change in the norm of the update vector was less than $10^{-5}$. Heritabilities for the mastitis traits were based on results from univariate analyses of each trait and were calculated as

$$
h^{2}=\frac{4 \sigma_{\text {sire }}^{2}}{\left(\sigma_{\text {sire }}^{2}+\sigma_{e}^{2}\right)},
$$

whereas the heritability of LASCC170 was adopted from Sørensen et al. (2009b). Phenotypic standard deviations to be used in estimation of response to selection were adopted from the DMU analyses.

\section{RESULTS}

\section{Economic Values}

Economic values per mastitis case differed among the pathogen-specific mastitis traits (Table 6). Costs ranged from $€ 149$ to $€ 570$ per case and were higher for contagious than environmental pathogens. The highest cost was associated with mastitis caused by Staph. aureus and CNS, followed by E. coli, Strep. dysgalactiae, and Strep. uberis. The average cost of a case of unspecific mastitis (€231) was lower than a case of Staph. aureus or CNS mastitis but higher than the remaining pathogens.

The effect of eliminating a pathogen on lactation milk yield per cow was greatest for Staph. aureus $(1,491 \mathrm{~kg} /$ case). For the remaining pathogens the effect was 938, 
Table 6. Results from estimation of economic values $(€)$ for different mastitis traits using SimHerd IV (Østergaard, 2005)

\begin{tabular}{lcc}
\hline Trait & $\begin{array}{c}\text { Estimated } \\
\text { incidence }\end{array}$ & $\begin{array}{c}\text { Cost per } \\
\text { case, } €\end{array}$ \\
\hline Unspecific mastitis & 0.242 & $231^{1}$ \\
Staphylococcus aureus & 0.050 & 570 \\
CNS & 0.050 & 380 \\
Escherichia coli & 0.022 & 206 \\
Streptococcus dysgalactiae & 0.017 & 149 \\
Streptococcus uberis & 0.028 & 149 \\
\hline
\end{tabular}

${ }^{1}$ This value was also used for unspecific residual mastitis.

685, 637, and $241 \mathrm{~kg} /$ case for CNS, E. coli, Strep. dysgalactiae, and Strep. uberis, respectively. The amount of discarded milk per case was largest for CNS (187 $\mathrm{kg}$ /case), whereas it was $129,124,113$, and $102 \mathrm{~kg} /$ case for Staph. aureus, Strep. uberis, E. coli, and Strep. dysgalactiae, respectively. The last milk-related factor that differed among the pathogens was the proportion of delivered milk with SCC $<200,000$ before and after a pathogen was eliminated (scenario 1-1 vs. scenarios 1-2 to 1-6). The proportion changed the most for CNS (0.09) and Staph. aureus (0.05). The change was smaller (0.01) for Strep. dysgalactiae and Strep. uberis, whereas it was unchanged for E. coli. The estimated amount of withdrawn milk and proportion of delivered milk with SCC $<200,000$ for unspecific mastitis was $121 \mathrm{~kg} /$ case and 0.18 , respectively.

Elimination of a mastitis type from the model herd increased feed costs because of an increase in milk yield. The total increase in feed costs was between $€ 139$ (Strep. uberis) and €1,263 (Staph. aureus) per mastitis case. Elimination of unspecific mastitis increased the feed costs by $€ 569$ per case.

\section{Genetic and Phenotypic Parameters}

Genetic and phenotypic parameters from the linear analysis of the mastitis traits and LASCC170 are presented in Table 7 . The heritabilities of the pathogen-specific mastitis $\left(h^{2}=0.005-0.021\right)$ were in all cases lower than the heritability of unspecific mastitis $\left(h^{2}=0.062\right)$. The heritability of residual mastitis was estimated as $h^{2}$ $=0.016$. Despite the low values, all heritabilities were different from zero $(P<0.05)$ when standard errors of the estimates were considered. Genetic correlations between the traits were high $\left(\mathrm{r}_{\mathrm{a}}=0.58-0.99\right)$, being lowest between mastitis caused by Staph. aureus and E. coli and highest between unspecific mastitis and residual mastitis.

\section{Genetic Superiority}

The difference in selection differentials (Table 8) between an index consisting of unspecific mastitis only and an index including several pathogen-specific mastitis traits and residual mastitis without considering LASCC170 was marginal. The difference was €0.4 or $<1 \%$ relative difference in favor of the unspecific index. When LASCC170 was included in the indices, the selection differential was $€ 0.4$ better for the pathogenspecific index than for the unspecific index, but again the relative difference was marginal $(<1 \%)$. The gain of including LASCC170 was largest for the pathogenspecific index. Here the increase in selection differential was $€ 1.8$ or $4 \%$. For the unspecific index the increase was $€ 1.1$ or $2.5 \%$.

Changing the number of daughters to either 50 or 130 did not change ranking of the indices with respect to $S$ and $r_{\mathrm{IA}}^{2}$, although the values were either reduced (50 daughters) or increased (130 daughters). The reliabilities of the 4 selection indices ranged from 0.62 to 0.67 ( $\mathrm{n}$ of daughters $=80$ ) and were directly proportional to $S$.

\section{DISCUSSION}

\section{Economic Values}

In the present study, clear differences between mastitis costs related to different pathogens were found. Pathogens such as Staph. aureus and CNS (considered

Table 7. Heritabilities (bold, on diagonal), genetic correlations (above diagonal), and phenotypic correlations (below diagonal) used for estimation of selection differential

\begin{tabular}{lcllccccc}
\hline Trait $^{1}$ & MAS UNSP & AUR & CNS & COL & DYS & UBE & MAS RES & LASCC170 \\
\hline MAS UNSP & $\mathbf{0 . 0 6 2}$ & 0.90 & 0.92 & 0.87 & 0.94 & 0.90 & 0.99 \\
AUR & 0.17 & $\mathbf{0 . 0 0 5 0}$ & 0.81 & 0.58 & 0.94 & 0.72 & 0.89 \\
CNS & 0.16 & 0.013 & $\mathbf{0 . 0 0 7 4}$ & 0.75 & 0.79 & 0.82 & 0.92 \\
COL & 0.17 & 0.0011 & 0.012 & $\mathbf{0 . 0 0 9 4}$ & 0.81 & 0.68 & 0.92 & 0.43 \\
DYS & 0.17 & 0.010 & 0.021 & -0.0062 & $\mathbf{0 . 0 0 7 3}$ & 0.91 & 0.87 & 0.49 \\
UBE & 0.18 & 0.0013 & 0.021 & 0.0038 & -0.0049 & $\mathbf{0 . 0 2 1}$ & 0.85 \\
MAS RES & 0.36 & -0.048 & -0.044 & -0.048 & -0.045 & -0.050 & $\mathbf{0 . 0 1 6}$ & 0.65 \\
LASCC170 & 0.13 & 0.028 & 0.0030 & 0.0048 & 0.0039 & 0.0099 & 0.024 & 0.67 \\
\hline
\end{tabular}

${ }^{1} \mathrm{MAS}$ UNSP $=$ unspecific mastitis $; \mathrm{AUR}=$ Staphylococcus aureus $; \mathrm{COL}=$ Escherichia coli $;$ DYS $=$ Streptococcus dysgalactiae $;$ UBE $=$ Streptococcus uberis; MAS RES = residual unspecific mastitis; LASCC170 = lactation average SCC from 5 to $170 \mathrm{~d}$ after first calving. 
Table 8. Total economic superiority $(€)$ of selected animals $(S)$ and reliability $\left(r_{\text {IA }}^{2}\right)$ for combinations of 4 different selection indices ${ }^{1}$ and different number of daughters $(\mathrm{n}=50,80$, or 130$)$

\begin{tabular}{lcccccccc}
\hline & \multicolumn{3}{c}{$S$} & & & \multicolumn{3}{c}{$r_{\text {IA }}^{2}$} \\
\cline { 2 - 4 } \cline { 6 - 8 } Index scenario & 50 & 80 & 130 & & 50 & 80 & 130 \\
\hline Direct selection for unspecific mastitis & 41.7 & 44.7 & 47.6 & & 0.55 & 0.63 & 0.71 \\
Direct selection for pathogen-specific mastitis & & 41.4 & 44.3 & 47.2 & & 0.54 & 0.62 & 0.70 \\
Direct selection for unspecific mastitis + SCC & & 43.4 & 45.8 & 48.2 & & 0.59 & 0.66 & 0.73 \\
Direct selection for pathogen-specific mastitis + SCC & & 43.7 & 46.1 & 48.4 & & 0.60 & 0.67 & 0.73 \\
\hline
\end{tabular}

${ }^{1}$ The breeding goal included 5 pathogen-specific mastitis traits and residual mastitis with economic values given in Table 6 .

contagious) were associated with much higher costs than pathogens such as E. coli, Strep. dysgalactiae, and Strep. uberis (considered environmental). The large differences between contagious and environmental pathogen are likely related to subclinical mastitis. In the present study, the risk of a case being subclinical was defined to be much larger for Staph. aureus and CNS ( 0.83 and 0.77 relative to the risk of a moderate clinical case, respectively) than for the remaining pathogens. This factor had a large effect on milk loss related to mastitis, which was considerably larger for Staph. aureus and CNS compared with Strep. dysgalactiae and Strep. uberis. This agrees with results of Rasmussen et al. (2007), where a reduction in milk yield was observed as early as 4 wk before clinical mastitis caused by Staph. aureus and CNS was discovered compared with noninfected quarters from the same cow. This suggests a prior subclinical infection. For E. coli, Strep. dysgalactiae, and Strep. uberis, decrease in milk yield was not observed until $1 \mathrm{wk}$ before the time clinical mastitis was detected. A large milk loss was also estimated for $E$. coli in the present study. This observation was related to the risk of a case being severe, which was twice as large for E. coli than for Staph. aureus but was the same as for Strep. uberis. Also, the risk of permanent reduction of milk yield was far larger for $E$. coli than for the remaining pathogens. In Rasmussen et al. (2007), the largest reduction in milk yield, 1 mo after a clinical mastitis case had been detected, was observed for E. coli and Strep. dysgalactiae. Milk loss related to infection with Strep. dysgalactiae did not reflect this observation in the present study.

Elevated SCC is a well-known consequence of subclinical and clinical mastitis caused by pathogens such as Staph. aureus and CNS (e.g., Shoshani et al., 2000; Pyörälä and Taponen, 2009) and is associated with reduced milk quality. In the present study, reduced milk quality was associated with elevated BTSCC, which reduces income from milk sale. Elimination of Staph. aureus and CNS from the model herd had the largest effect on BTSCC as expressed by the proportion of sold milk with SCC $<200,000$ cells/mL. Elimination of E. coli mastitis did not change this proportion, most likely because $E$. coli is usually associated with clinical mastitis cases of short duration, which causes only short, temporary increments of SCC (De Haas et al., 2002).

The average cost related to unspecific mastitis was lower than expected because a weighted average of the costs of the pathogen-specific traits would have resulted in a value of $€ 348$. Assuming that production conditions are similar in Denmark and Sweden, the estimated economic value for unspecific mastitis was comparable to the estimate (€275) given by Nielsen (2009) for Swedish conditions, where values for clinical and subclinical mastitis were assessed simultaneously as in the present study. The lower value in the present study is likely to be related to the difference in incidence between unspecific mastitis and the pathogen-specific mastitis traits. This is because as the incidence of mastitis increases, the risk of a case being from the same cow also increases in SimHerd IV. Therefore, the costs related to milk loss are reduced (in the present study, the estimated milk loss was $55 \%$ lower for unspecific mastitis compared with Staph. aureus mastitis). However, the incidence used in the present study for unspecific mastitis was based on first treatments only. It would have been more correct to use the total number of treatments per cow to ensure more realistic modeling and data assumptions. The reason for not doing this was that it was possible to use the first treatment only for pathogen-specific traits because information about pathogen status was not known for all recorded mastitis treatments. Therefore, the total number of treatments for each pathogen was unknown. Estimates for the pathogen-specific mastitis types were less likely to be biased because of the low incidence of these traits.

The parameters for the simulation model used in the present study were adopted from Østergaard et al. (2005), who had used available literature to determine them. In their study, it was clear that it was impossible to find pathogen-specific parameters in all cases. Finding correct modeling parameters for unspecific mastitis 
is not trivial because this trait is a mix of different pathogen-specific traits. In the present study, we used a simple weighted average of the pathogen-specific parameters. However, it may be possible to establish better parameters from real data for both unspecific and pathogen-specific mastitis, although this would require quite extensive studies in some cases and in other cases it is simply a matter of analyzing records of mastitis data in the national database.

The economic value of 1 case of unspecific mastitis in first lactation has been estimated at $€ 145$ in the background material for the new Nordic Total Merit index (Pedersen et al., 2008). The reason this estimate is different from the $€ 231$ in the present calculations is that reduced yield later in the lactation was not included in the Nordic Total Merit calculations. This reduces the economic value of mastitis. On the other hand, higher values for treatment costs and extra labor associated with sick animals were included in these calculations. In the present study, we used the derived economic values as economic weights in a selection index. When economic values are used for this type of calculation, the absolute values are less interesting in contrast to the differences between values. Assuming that the amount of extra labor associated with a case of mastitis is unaffected by the mastitis type, results from the investigated selection indices in the present study would remain unchanged if extra labor was included in the simulation model.

\section{Estimated Genetic and Residual Parameters}

The selection indices in the present studies were based on genetic parameters (Table 7) estimated from linear models for the mastitis traits. This resulted in very low heritabilities, but all greater than zero, for the pathogen-specific mastitis traits. Genetic parameters (heritabilities, genetic and phenotypic correlations) for the mastitis traits and LASCC170 were also estimated by Sørensen et al. (2009a,b) based on the same data. However, these parameters had been estimated on the underlying nonobservable scale using threshold models. Because the economic values and phenotypic standard deviations for the mastitis traits were on the observable scale, new estimates had to be derived.

It is possible to transform heritabilities from the observable scale to the underlying unobservable scale and vice versa using the formula provided by Dempster and Lerner (1950). Use of this formula on the heritabilities estimated by Sørensen et al. (2009a) gave heritabilities on the observable scale values close to those estimated in the present study. Mäntysaari et al. (1991) compared variance and covariance components for 2 binary traits estimated with a linear model and a threshold model.
They concluded that both models performed equally well for estimation of heritabilities. They also concluded that both models produced similar genetic correlations without any need of correction for incidence. In the present study, the genetic correlations between the pathogen-specific traits estimated using a linear model were larger than the threshold model estimates on the underlying scale presented by Sørensen et al. (2009a) using the same data. The reason for this may be the low incidences for the pathogen-specific mastitis traits, which were lower than the lowest incidence $(5 \%)$ used in Mäntysaari et al. (1991). Regarding the residual correlations, Mäntysaari et al. (1991) did not find comparable estimates between the linear model and the threshold model, and this discrepancy was particularly pronounced for incidences below $25 \%$. The residual correlations between the pathogen-specific mastitis traits estimated in the present study were in general lower than the residual correlation estimated using a threshold model (Sørensen et al., 2009a). However, transformation may be possible using the formula given by Vinson et al. (1976). Lower genetic correlations among different pathogen-specific mastitis traits would result in greater advantage, with respect to $S$, of considering unspecific rather than pathogen-specific mastitis traits in the selection index. On the other hand, higher heritabilities of the pathogen-specific mastitis traits relative to the heritability of unspecific mastitis would reduce the advantage of an unspecific index. Here, these 2 phenomena probably counterbalance each other because the genetic correlations among the pathogen-specific mastitis traits were high compared with estimates found by Sørensen et al. (2009a,b).

\section{Genetic Superiority}

Given the results from the present study of selection differentials of either a pathogen-specific or an unspecific index (without considering LASCC170), no clear distinctions could be made between the 2 types of indices. The reason that the pathogen-specific udder health index did not prove superior to an unspecific udder health index is primarily the very low heritabilities of the pathogen-specific traits compared with the heritability of susceptibility to unspecific mastitis.

Inclusion of LASCC170 as a correlated trait was slightly more beneficial for the pathogen-specific index. However, the pathogen-specific index gave only slightly higher selection differential compared with the unspecific index when LASCC170 was considered. The explanation is that inclusion of LASCC170 makes up for the lower heritabilities of pathogen-specific mastitis compared with unspecific mastitis. However, the possible advantage of genetic correlation $<1$ among the patho- 
gen-specific traits is unaffected by inclusion of LASCC170. Considering pathogen-specific rather than unspecific mastitis in the selection index is expected to be most advantageous with respect to $S$ when genetic correlations among pathogen-specific traits are close to zero and when the differences between heritabilities for unspecific and pathogen-specific traits are as small as possible. However, the relative importance of differences in heritabilities decreases when correlated information for LASCC170 is considered, or when the number of progeny or other information increases. However, the latter was not the case in the present study. The maximum (when $r_{I A}^{2}=1$ ) selection differential of the breeding goal was in all cases $S=56.5$. The reliabilities were high because we had information about mastitis from all information sources.

Better data quality could be another way to improve a selection index based on pathogen-specific mastitis traits. At present, we do not have pathogen information on the majority of the recorded mastitis treatments; therefore, heritabilities on the observable scale are underestimated because of the relation to incidences of the different pathogens. However, routine use of new technologies such as mastitis real-time (RT)-PCR (Koskinen et al., 2009) enables large-scale collection of test-day data for the most common mastitis pathogens from all herds participating in the herd-testing schemes. This kind of data makes the use of records of mastitis treatments in breeding for improved mastitis resistance superfluous and the improved data quality may result in larger heritabilities of the pathogen-specific mastitis traits. Thus, in the future, a pathogen-specific mastitis index may prove to be superior to a mastitis index based on unspecific mastitis. At present, the cost associated with RT-PCR analysis of a milk sample approximately equals the costs of bacteriological analysis. However, if it is decided to do large-scale recording of pathogens, the costs of RT-PCR analysis may decrease considerably. New health agreement schemes in Denmark between veterinarians and dairy farmers require bacteriological analysis of milk samples from cows with mastitis before antibiotic treatment can be carried out. The number of herds participating in such schemes is increasing and this may also lead to increasing incidence of pathogenspecific mastitis relative to the incidence of unspecific mastitis

The results from the present study indicate that if the incidences of the single pathogens increase, the heritability of the pathogen-specific traits will increase too, thus increasing the difference in response to selection in favor of a pathogen-specific udder health index. Also, use of genome-wide markers may make it more attractive to consider pathogen-specific instead of unspecific mastitis traits because high accuracy of genomic breeding values can be obtained for traits with low heritability (e.g., Muir, 2007).

\section{CONCLUSIONS}

Results of the present study showed different costs associated with mastitis caused by different pathogens. Thus, a pathogen-specific udder health index would be advantageous because more weight can be put on pathogens associated with high costs relative to pathogens associated with low costs. However, the difference between selection differentials of an unspecific and a pathogen-specific udder health index was marginal, mainly because of very low heritability of pathogenspecific mastitis traits relative to the heritability of unspecific mastitis. New technologies for identifying pathogens, such as RT-PCR, and increased numbers of dairy herds participating in health agreement schemes may increase the incidence of pathogen-specific mastitis relative to unspecific mastitis. This will automatically lead to higher heritabilities of pathogen-specific mastitis and a higher selection differential of a pathogenspecific udder health index relative to an unspecific udder health index.

\section{ACKNOWLEDGMENTS}

Data for this study were kindly provided by the Danish Cattle Federation (Aarhus, Denmark).

\section{REFERENCES}

Danish Cattle Association. 2009. Årsstatistik avl-2008/09. http:// www.lr.dk/kvaeg/diverse/aarsstat2009.pdf. Accessed Jun. 20, 2009.

De Haas, Y., H. W. Barkema, and R. F. Veerkamp. 2002. The effect of pathogen-specific clinical mastitis on the lactation curve for somatic cell count. J. Dairy Sci. 85:1314-1323.

Dempster, E. R., and I. M. Lerner. 1950. Heritability of threshold characters. Genetics 35:212-236.

Halasa, T., K. Huijps, O. Østerås, and H. Hogeveen. 2007. Economic effects of bovine mastitis and mastitis management: A review. Vet. Q. 29:18-31.

Hazel, L. N. 1943. The genetic basis for constructing selection indexes. Genetics 28:476-490.

Heringstad, B., G. Klemetsdal, and J. Ruane. 2000. Selection for mastitis resistance in dairy cattle: A review with focus on the situation in the Nordic countries. Livest. Prod. Sci. 64:95-106.

Jensen, J., E. A. Mäntysaari, P. Madsen, and R. Thompson. 1997. Residual maximum likelihood estimation of (co)variance components in multivariate mixed linear models using average information. J. Ind. Soc. Agric. Stat. 49:215-236.

Johansson, K., S. Eriksson, J. Pösö, M. Toivonen, U. S. Nielsen, J.-Å. Eriksson, and G. P. Aamand. 2006. Genetic evaluation of udder health traits for Denmark, Finland and Sweden. Pages 92-96 in Proc. 2006 Interbull Mtg., Kuopio, Finland. Interbull Bull. no. 35. Interbull, Uppsala, Sweden.

Koskinen, M. T., J. Holopainen, S. Pyörälä, P. Bredbacka, A. Pitkälä, H. W. Barkema, R. Bexiga, J. Roberson, L. Sølverød, R. Piccinini, D. Kelton, H. Lehmusto, S. Niskala, and L. Salmikivi. 2009. 
Analytical specificity and sensitivity of a real-time PCR assay for identification of bovine mastitis pathogens. J. Dairy Sci. 92:952959.

Madsen, P., and J. Jensen. 2006. A user's guide to DMU. A package for analyzing multivariate mixed models. Version 6 , release 4.7. University of Aarhus, Faculty of Life Sciences, Department of Genetics and Biotechnology, Research Centre Foulum, Tjele, Denmark.

Mäntysaari, E. A., R. L. Quaas, and Y. T. Gröhn. 1991. Simulation study on covariance component estimation for two binary traits in an underlying continuous scale. J. Dairy Sci. 74:580-591.

Muir, W. M. 2007. Comparison of genomic and traditional BLUPestimated breeding value accuracy and selection response under alternative trait and genomic parameters. J. Anim. Breed. Genet. 124:342-355.

Nielsen, C. 2009. Economic impact of mastitis in dairy cows. PhD Thesis, Swedish Univ. Agric. Sci., Uppsala, Sweden.

Østerås, O., H. Solbu, A. O. Refsdal, T. Roalkvam, O. Filseth, and A. Minsaas. 2007. Results and evaluation of thirty years of health recordings in the Norwegian dairy cattle population. J. Dairy Sci. 90:4483-4497.

Østergaard, S., M. G. G. Chagunda, N. C. Friggens, T. W. Bennedsgaard, and I. C. Klaas. 2005. A stochastic model simulating pathogen-specific mastitis control in a dairy herd. J. Dairy Sci. 88:4243-4257.

Pedersen, J., M. K. Sørensen, M. Toivonen, J.-Å. Eriksson, and G. P. Aamand. 2008 Report on an economic basis for a Nordic total merit index. http://www.nordicebv.info/Publications/English/ publicatuions+ny.htm. Accessed Jun. 14, 2009.

Pyörälä, S., and S. Taponen. 2009. Coagulase-negative staphylococciEmerging mastitis pathogens. Vet. Microbiol. 134:3-8.

Rasmussen, M. D., T. W. Bennedsgaard, and L. H. Pedersen. 2007. Changes in quarter yield and milking frequency during clinical mastitis. Pages 214-215 in Proc. NMC 46th Ann. Meet. 2006., San Antonio, TX. NMC Inc.,Verona, WI.

Seegers, H., C. Fourichon, and F. Beaudeau. 2003. Production effects related to mastitis and mastitis economics in dairy cattle herds. Vet. Res. 34:475-491.

Seegers, H., C. Fourichon, J. T. Sørensen, P. Hortet, and D. Billon. 2000. Modelling for cost-benefits of prevention and control of mastitis in dairy herds. Pages 55-61 in Proc. Symp. Economic Modelling of Animal Health and Farm Management. Wageningen University, Wageningen, the Netherlands.

Shoshani, E., G. Leitner, B. Hanochi, A. Saran, N. Y. Shpigel, and A. Berman. 2000. Mammary infections with Staphylococcus aures in cows: Progress from inoculation to chronic infection and its detection. J. Dairy Res. 67:155-169.

Sørensen, L. P., P. Madsen, T. Mark, and M. S. Lund. 2009a. Genetic parameters for pathogen-specific mastitis resistance in Danish Holstein cattle. Animal 3:647-656.

Sørensen, L. P., P. Madsen, T. Mark, and M. S. Lund. 2009b. Genetic correlations between pathogen-specific mastitis and somatic cell count in Danish Holsteins. J. Dairy Sci. 92:3457-3471.

Steine, T. 1998. Realized effect of selection for mastitis resistance. Pages 115-117 in Proc. 1998 Interbull Mtg., Rotorua, New Zealand. Interbull Bull. No. 17. Interbull, Uppsala, Sweden.

Vinson, W. E., J. M. White, and R. H. Kliewer. 1976. Overall classification as a selection criterion for improving categorically scored components of type in Holsteins. J. Dairy Sci. 59:21042114.

Wagenaar, D., J. van Arendonk, and M. Kramer. 1995. Selection index program (SIP). User manual. Wageningen Agricultural University, Wageningen, the Netherlands. 